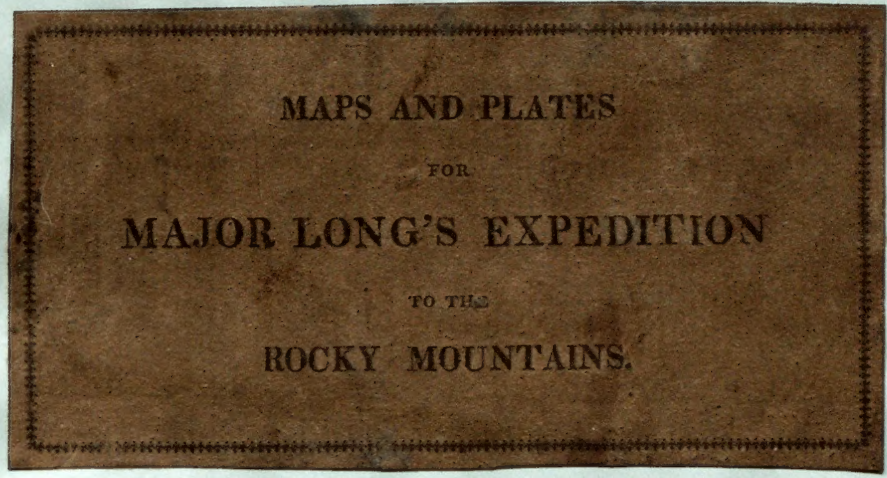




\section{AN EXPEDITION}

FROM

\section{PITTSBURGH TO 'THE ROCKY MOUN'TAINS}

PERFORMED IN THE YEARS 1819-20,

BY ORDER OF THE

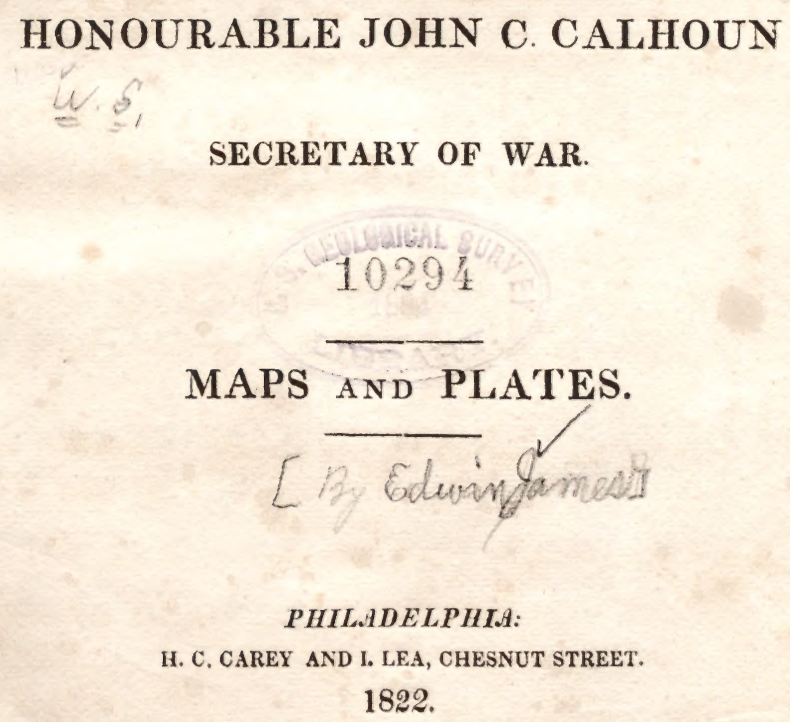




\title{
LIST OF THE ENGRAVINGS,
}

\author{
CONTAINING APPROPRIATE
}

\section{REFERENCES AND EXPLANATIONS.}

Map of the country drained by the Mississippi-Eastern section.

Map of the country drained by the Mississippi-Western section.

War dance in the interior of a Konza Lodge.-See Vol. I. page 135.

N. B. War dance has been inadvertently substituted for Dog dance, of which the plate is a representation.

Ото council.-See Vol. I. page 158.

View of the Rocky Mountains, on the Platte, 50 miles from their base.-See Vol. I. page 4.95 .

View of the Castle Rock, on a branch of the Arkansa, at the base of the Rocky Mountains.-See Vol. II. page 16.

Moveable skin lodges of the Kaskaias.-See Vol. I. page 206, and Vol. II. page 105.

Oto encampment.-See Vol. II. page 188. 
Indin record of a battle between the Pawnees and Konzas, as delineated on a blson noBE.- This delineation was copied by Mr. T. R. Peale from a bison robe presented to Major 0.Fallon at the Pawnee council, treated of in Vol. I. page 159, et seq. It serves to exhibit the state of the art of drawing amongst the Pawnee Indians, or rather amongst the Missouri Indians generally. The following is the subject of this sketch. A pedestrian warparty of eighteen Konzas approached the Pawnee villages for the purpose of capturing horses and taking scalps. Before their object was accomplished, they were discovered and attacked by a superior force of Pawnees on horseback, who, after an obstinate conflict, succeeded in destroying every individual of the party. In this sketch it will be remarked that 16 of the Pawnees are armed with shields which defend the whole body, with the exception of the head; the heads of many of the Pawnees are decorated with bison horns, and feathers, and others with feathers only. They are armed with spears, battle axes, and one or two fusees; one individual carries a flag of feathers, and one carries a whip; many of the horses are represented with human scalps depending from their mouths, an ornament very commonly seen on the horses of warriors; two of the horses are represented as branded.

The Konzas were armed with bows and arrows and fusees; nine are represented as decapitated, and the wounds are indicated by the flowing of blood from the wounded part: six scalps only remain on the robe, the others probably having been obliterated.

The figures were brilliantly coloured with red, yellow, black, and green, and those of the Pawnees were accompanied by some mark by which their names might be recognised.

An Ioway Indian, on seeing this robe, readily deciphered the whole.

For further illustration of this subject, see Vol. I, pages 287, 296, and 440.

View of the insulated table lands at the base of the Rocky Mountains.-See Vol. II. pp. $351,389,404$.

Geological Chart, containing vertical sections on the parallels of 35 and 41 degrees of north latitude.-See Vol. II. page 442. 


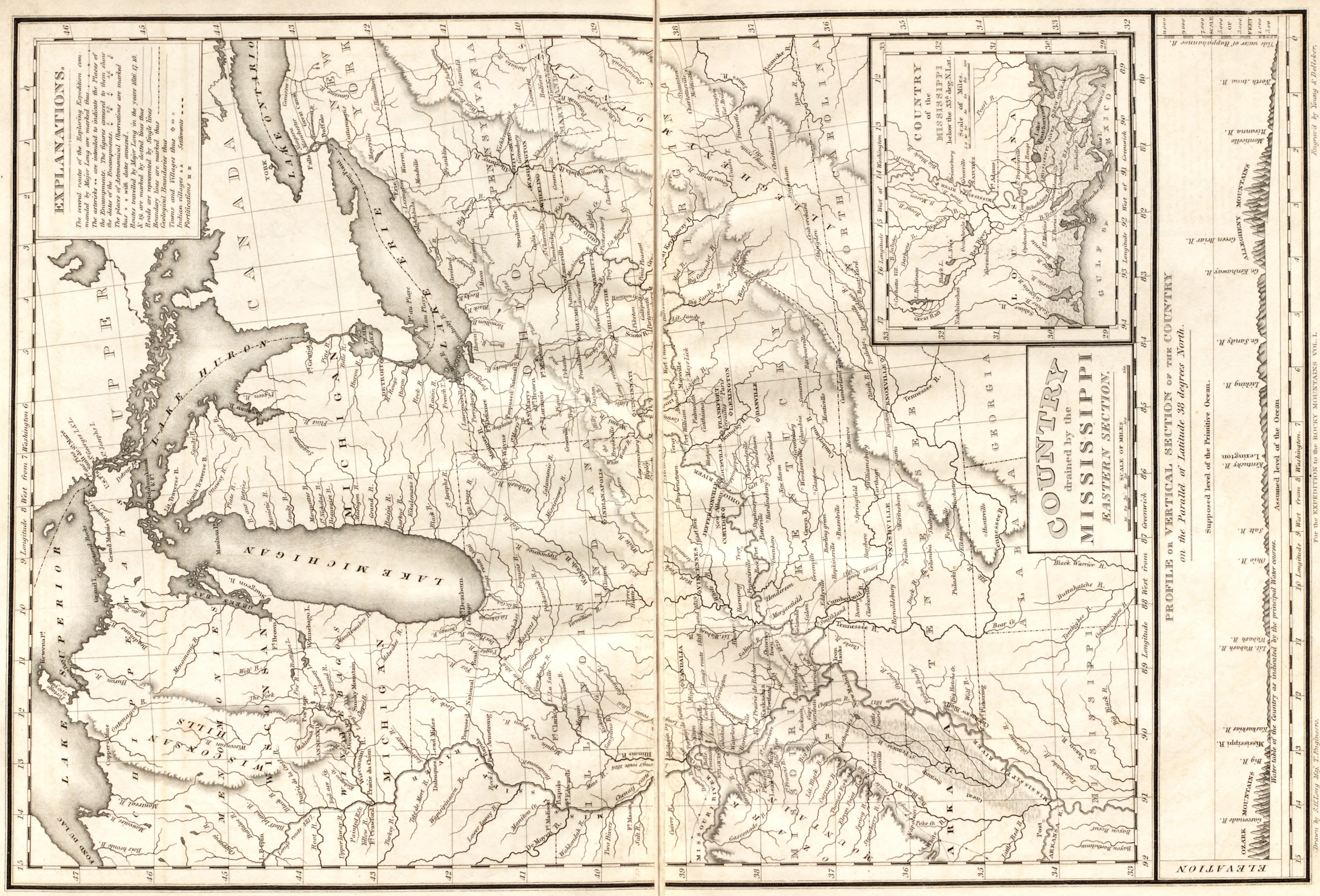




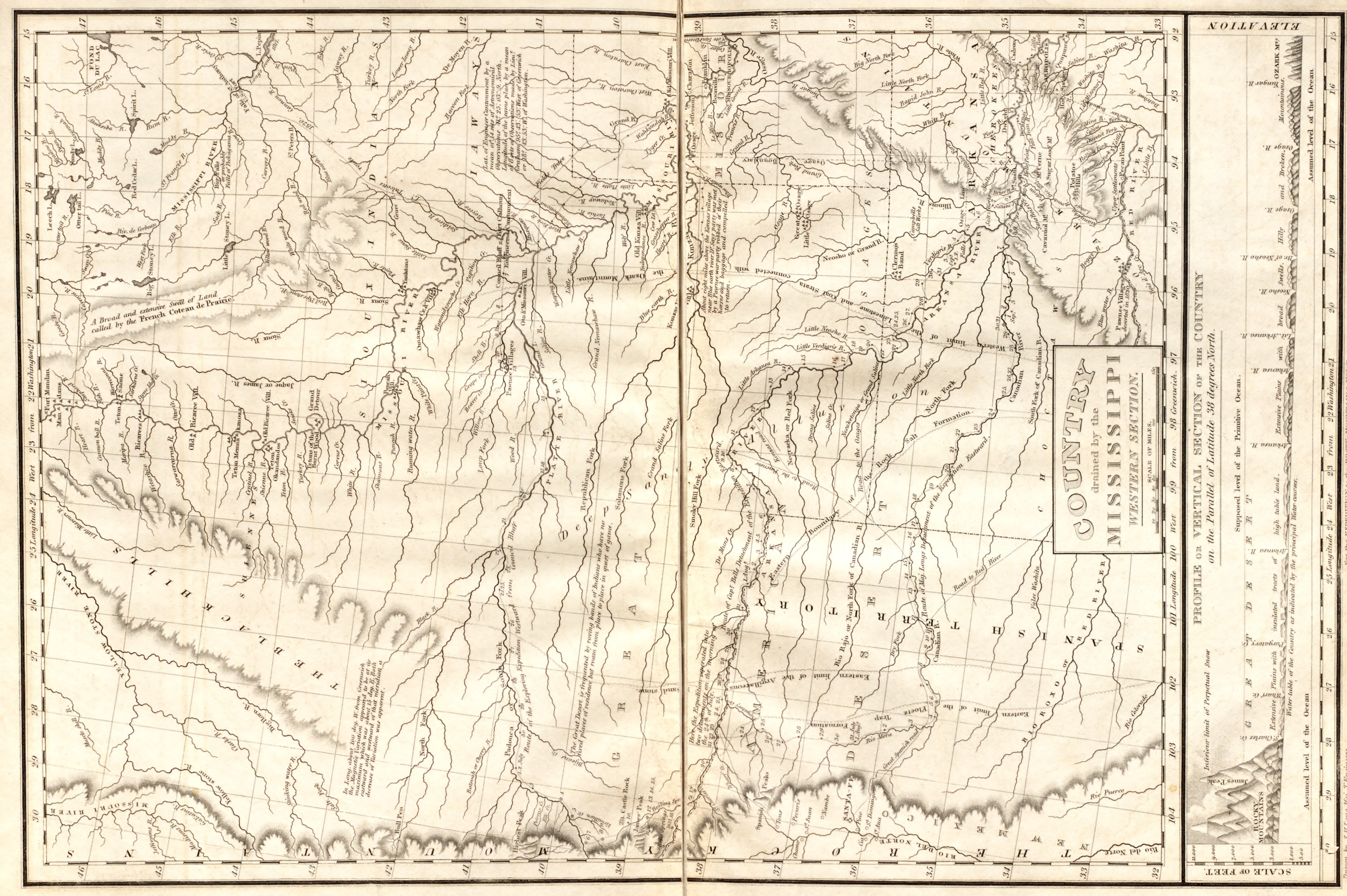




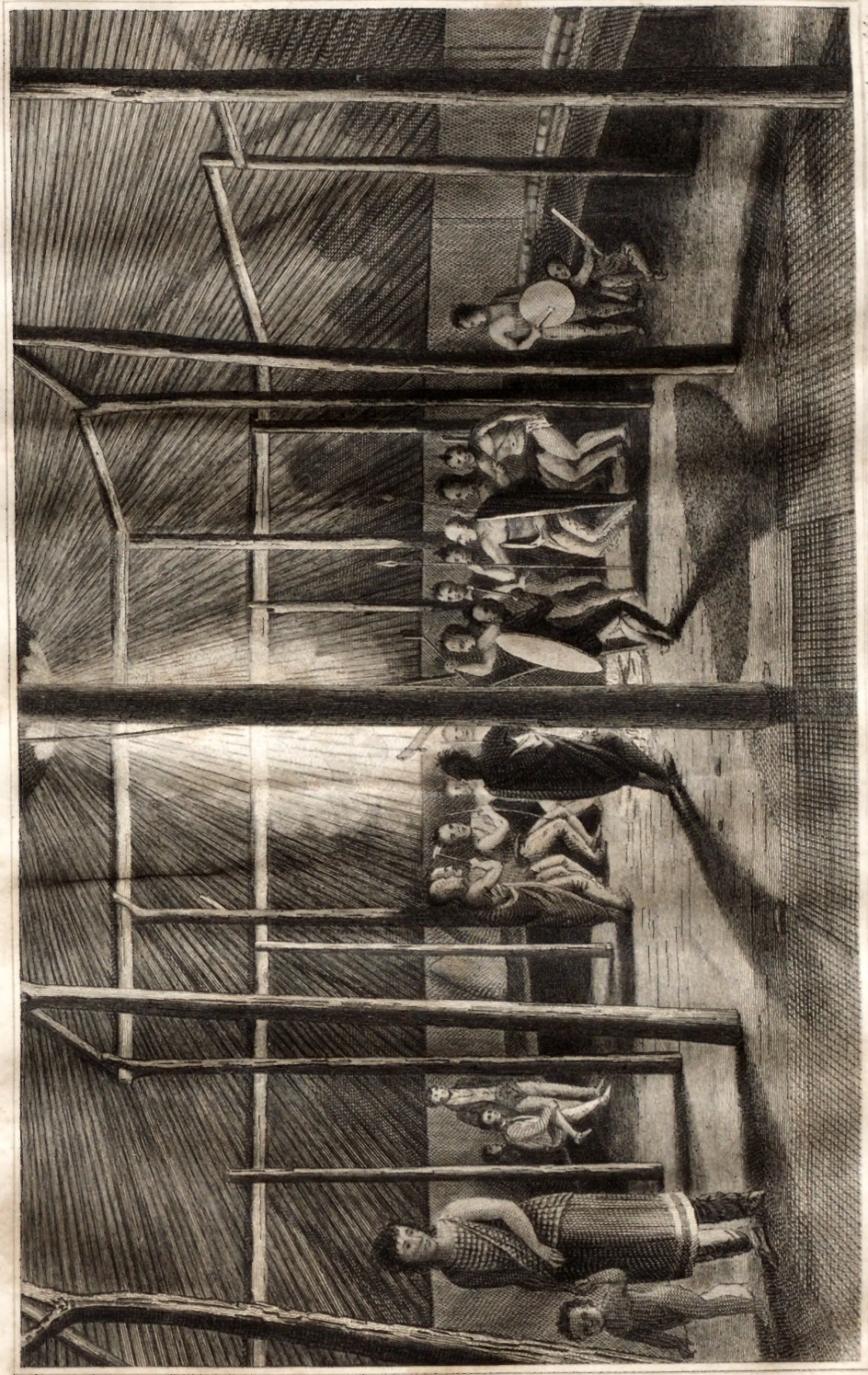




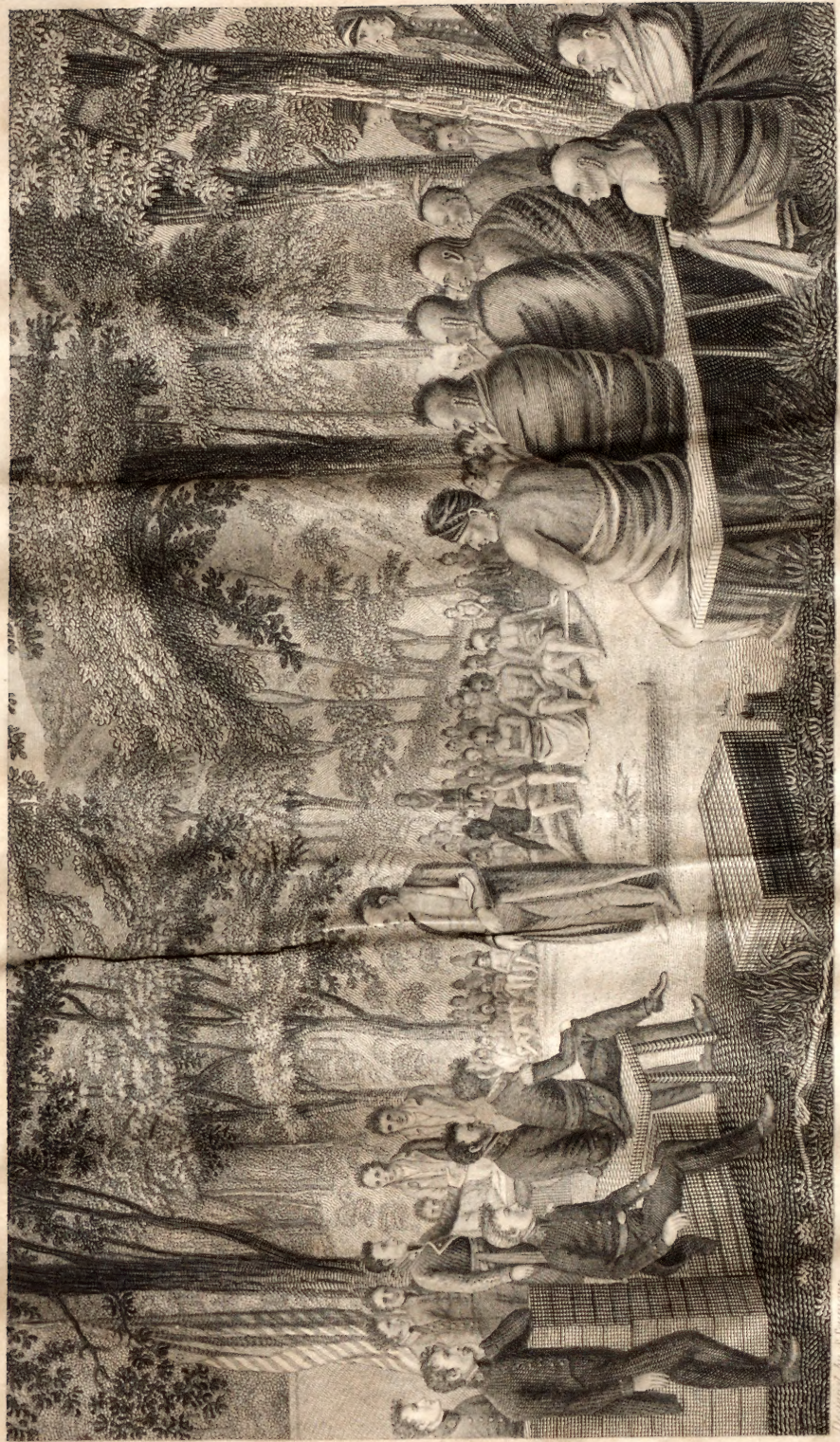




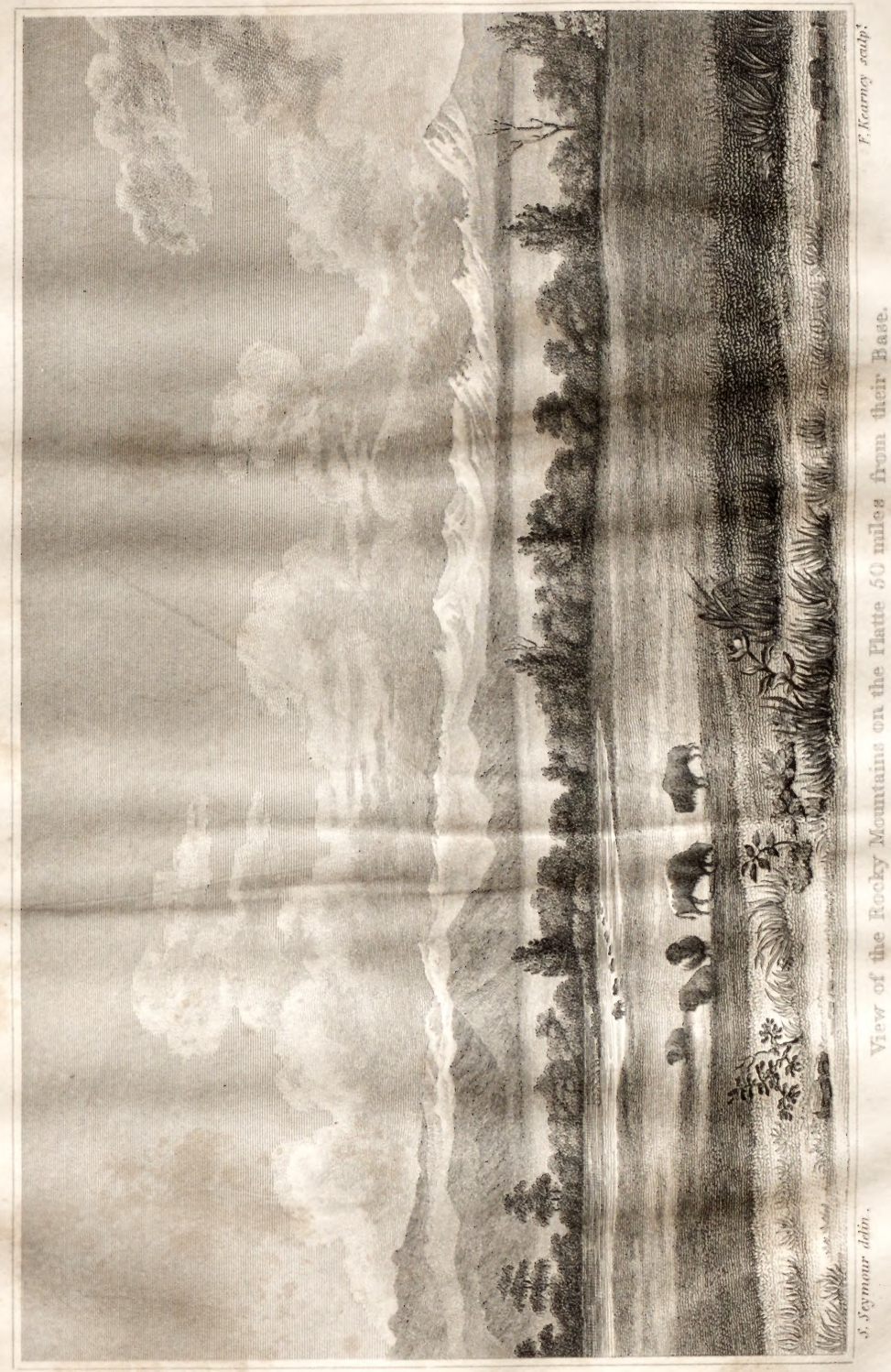




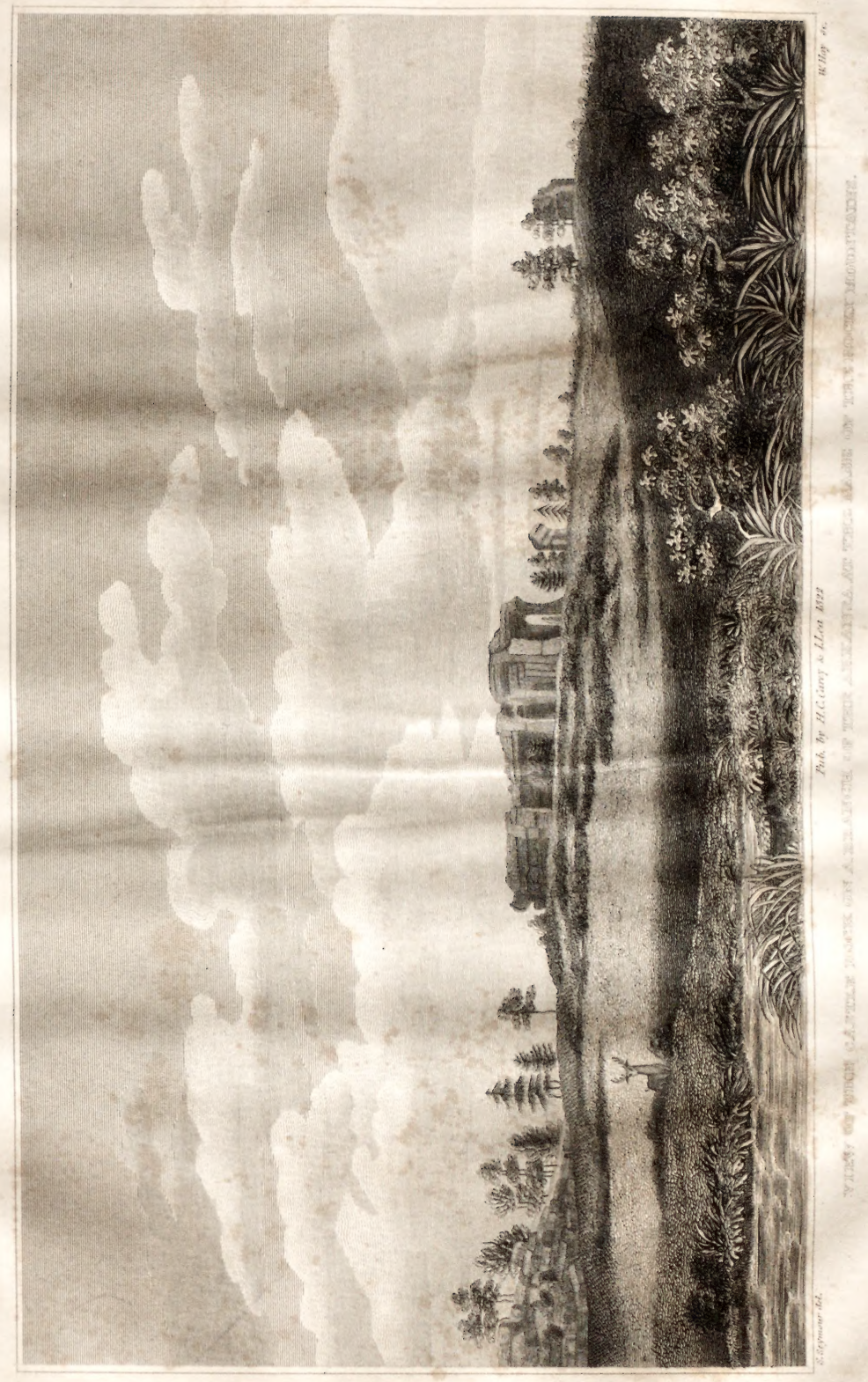




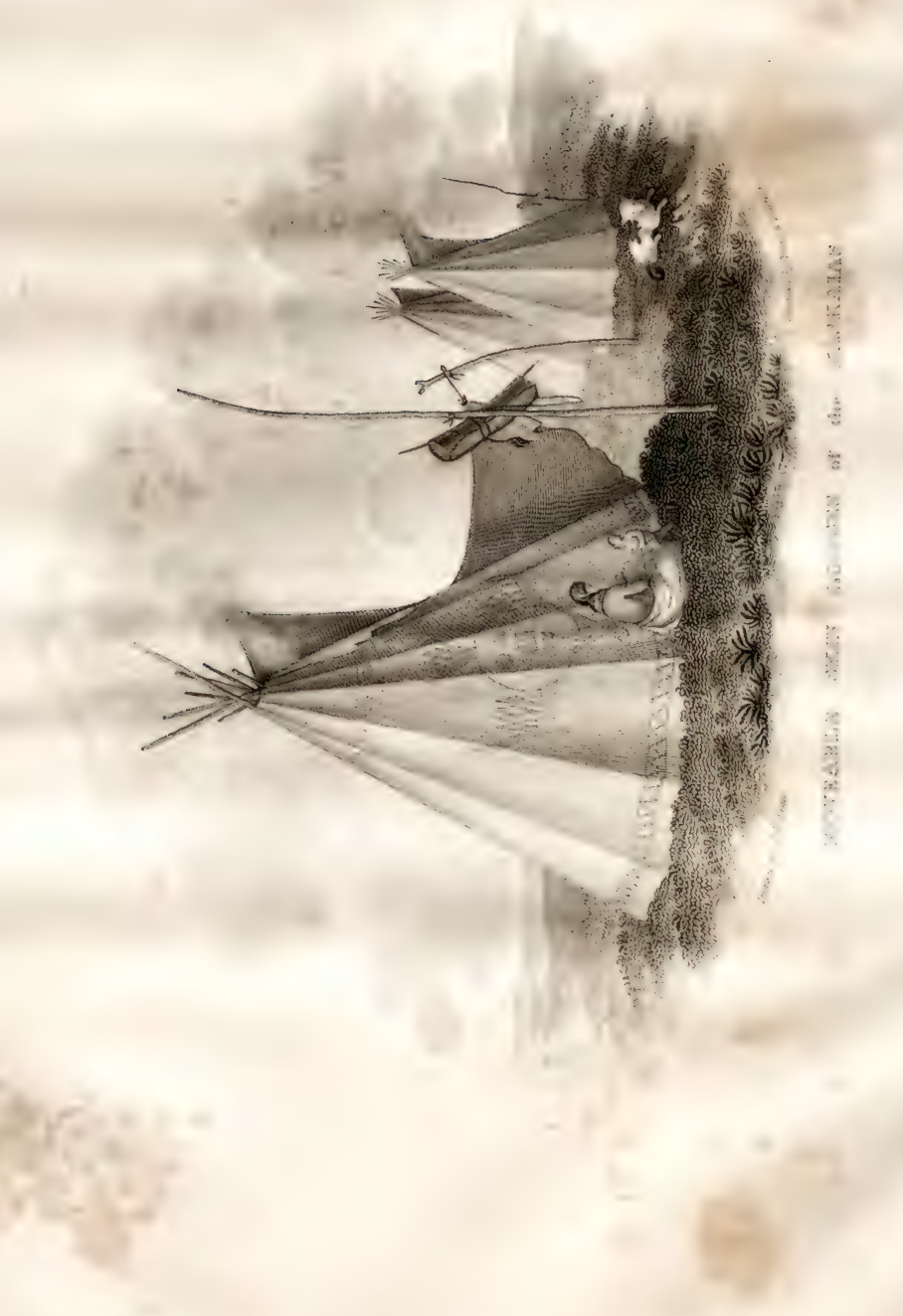




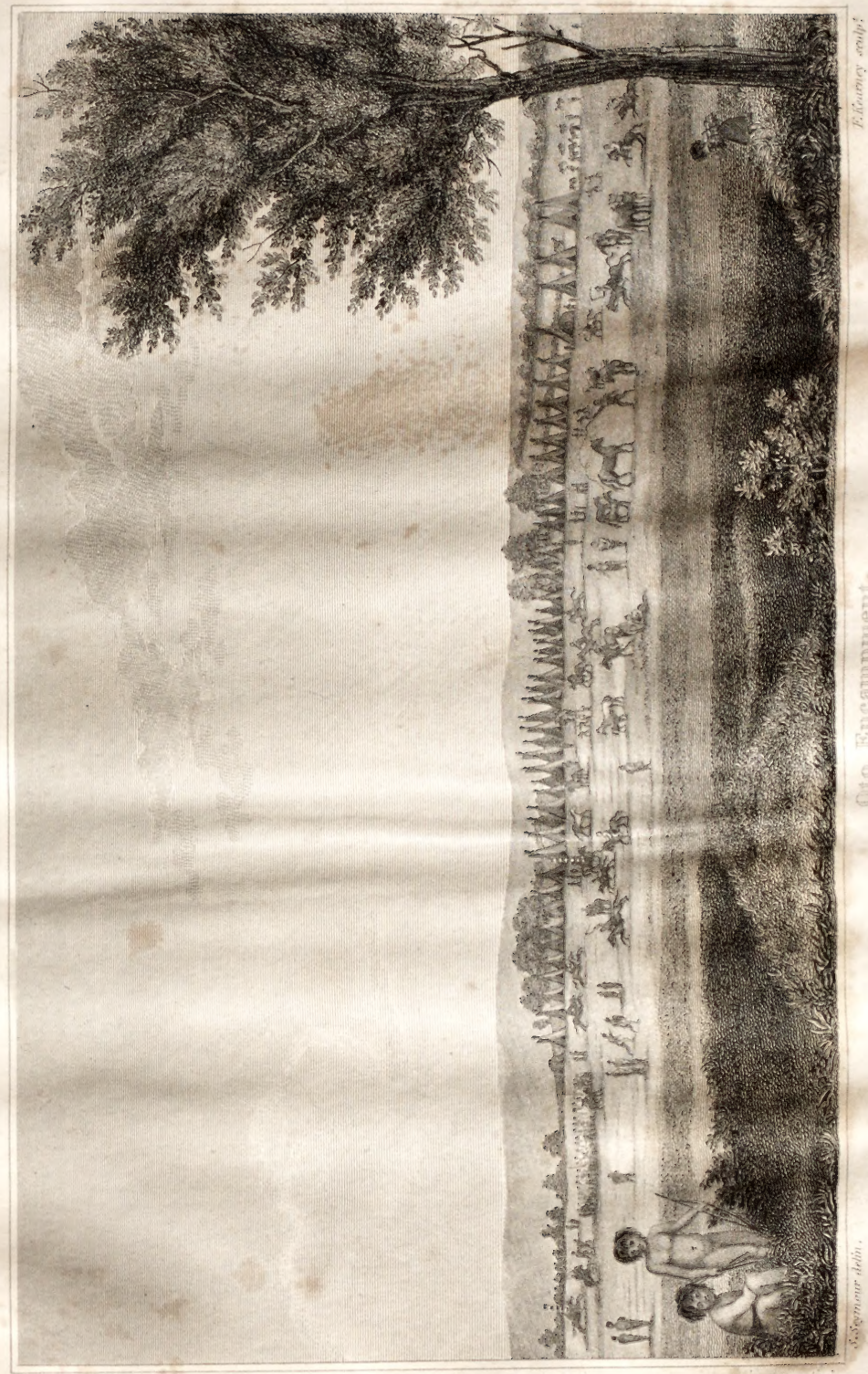




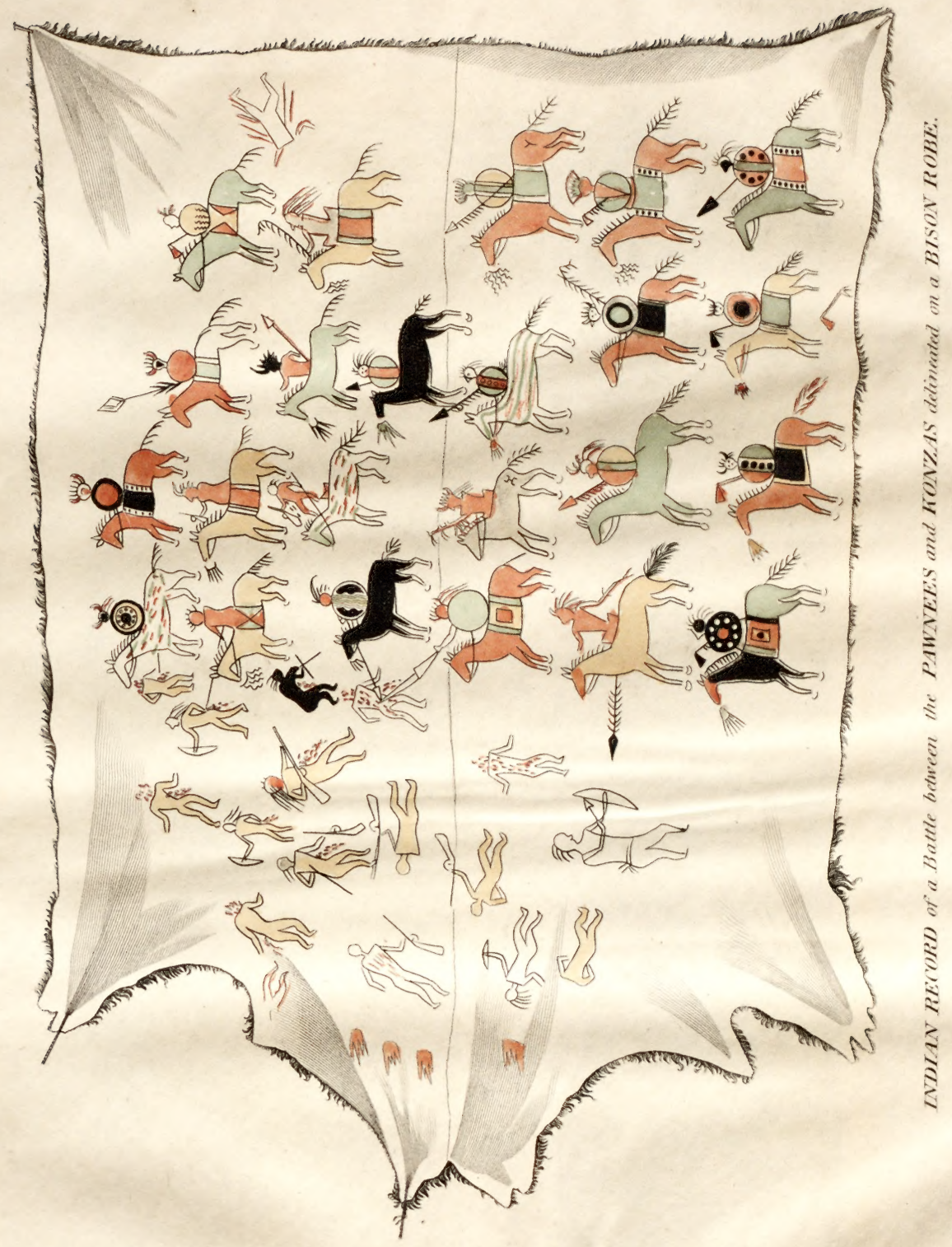




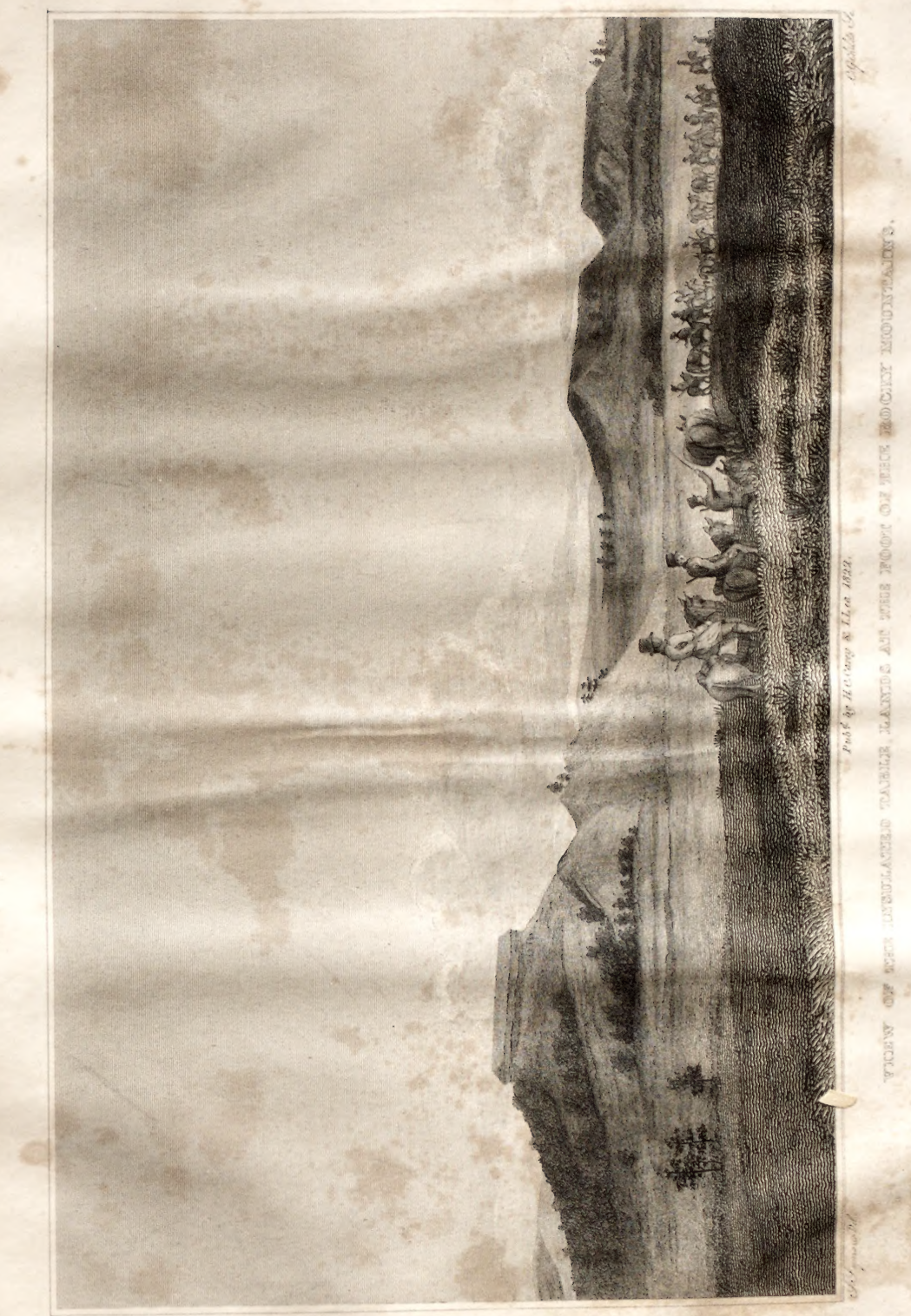




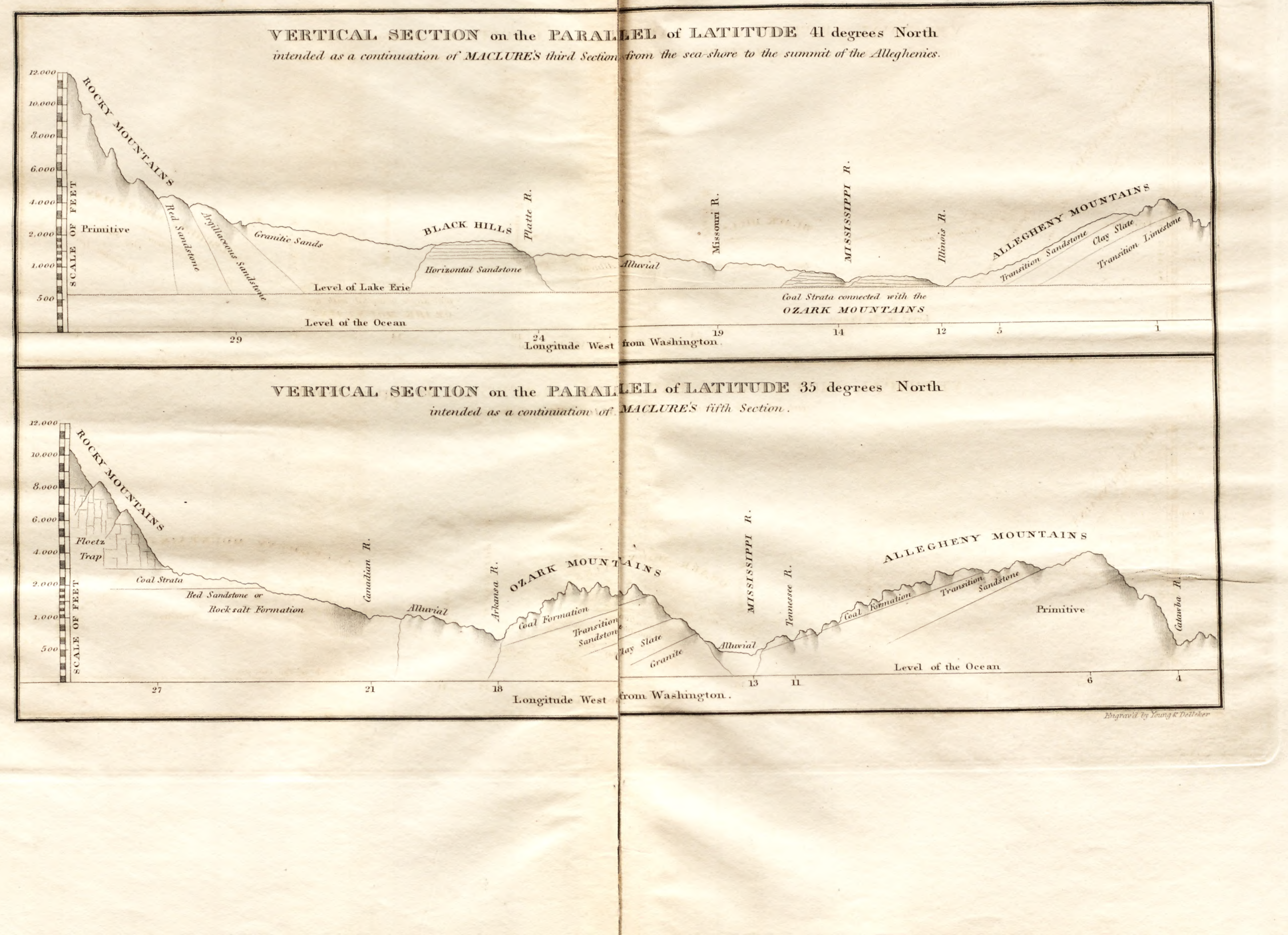

